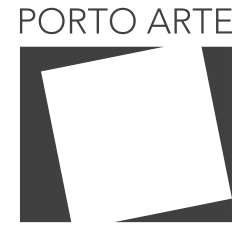

Revista de Artes Visuais

v.25 n. 43

Jan/jun 2020 e-ISSN: 2179-8001

\title{
CAMINHOS DA CURADORIA E O PÓS-MUSEU
}

\author{
Curatorial paths and the post-museum
}

\section{Joanna Brolhani}

ORCID: 0000-0003-0469-7610

Universidade do Estado de Santa Catarina

\section{Resumo}

$\mathrm{Na}$ obra Museums and the Interpretation of Visual Culture (2000), Eilean-Hooper-Greenhill discute a cultura da imagem na pedagogia museal, contrastando o modelo do museu modernista com o que ela chama de pós-museu. O presente ensaio busca discutir esse conceito, assim como o conceito de constelação pós-colonial de Okwui Enwezor, para desvelar gestos curatoriais a partir de uma situação específica observada em 2019 no Museu Oscar Niemeyer: um espaço de entressalas que abriga obras de três diferentes instituições (MON, MAC-PR e Bienal de Curitiba), provocando um diálogo sobre fronteiras, compromissos e desafios da prática curatorial e narrativas institucionais.

Palavras-chave

Curadoria. Pós-museu. Fronteiras. Bienal. Constelação pós-colonial.

\section{Abstract}

In the work Museums and the Interpretation of Visual Culture (2000), Eilean Hooper-Greenhill discusses image culture in museum pedagogy, from the modernist museum in contrast to what she calls the post-museum. The present essay aims to discuss this concept, as well as the concept of post-colonial constellation, by Okwui Enwezor, to unfold curatorial gestures from a specific situation observed in 2019 at Oscar Niemeyer Museum: a space among exhibition rooms that hosts three different institutions (MON, MAC-PR and Bienal de Curitiba) and provokes a dialog on borders, commitments and challenges of curatorial practices and institutional narratives.

Keywords

Curatorship. Post-museum. Borders. Biennal. Post-colonial constellation. 


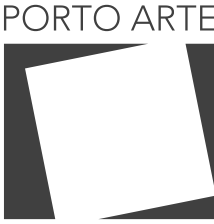

Revista de Artes Visuais

V. $25 \cap .43$

Jan/jun 2020 e-ISSN: 2179-8001
Figura 01 - Espaço expositivo no Museu Oscar Niemeyer, outubro 2019. Imagem da autora.
Ao caminhar pelo hall do Museu Oscar Niemeyer, nos deparamos com a seguinte frase: FÉ NA CRISE PAU NA GENTE logo na entrada da exposição "Pequenos Gestos Memórias Disruptivas" (2019-2020)‥ A obra, de Jorge Carlos Sade, é de 1984, mas poderia muito bem ter sido de 2014, 2016, 2017 ou 2019. Chama a atenção não somente essa frase, que é tão direta quanto um pixo num muro de rua, mas também o que estava ao redor. Logo na frente encontramos uma grande e colorida instalação de Lin Hongbo, curiosamente chamada: World of Fairytale [Mundo de Conto de Fadas] (2010-2014), obra que faz parte da $14^{a}$ Bienal de Curitiba (2019-2020) ${ }^{2}$. Esse mundo colorido é composto por esculturas de papel, e cada parte é esculpida revelando o contorno de um país diferente. Mas não é fácil distinguir isso imediatamente, pois as esculturas são posicionadas de diferentes formas, abrindo o contorno do país para revelar uma nova forma. Então estamos diante de um mundo encantador e de um mundo de crise e violência. Porém, o diálogo intercuratorial não-proposital apresenta mais uma mensagem: nos espia de cantinho o título da mostra de Geraldo Leão, "Declaração de Princípios" (2019) ${ }^{3}$.

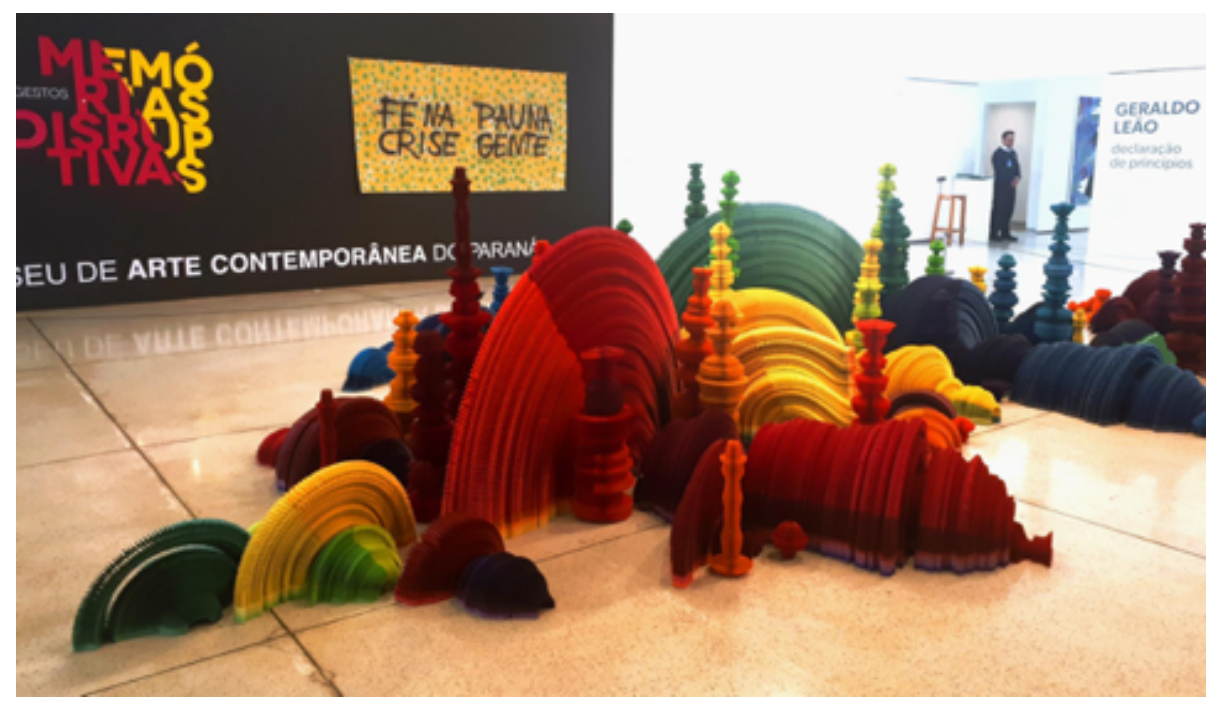

Que princípios seriam esses declarados nessa pluralidade de discursos?

Uma exposição é as obras que ela evidencia e o discurso curatorial que ela produz. Ela é emoldurada de formas físicas e imateriais: pelo edifício que a acolhe, pelas ações

\footnotetext{
1- Exposição realizada pelo Museu de Arte Contemporânea do Paraná (temporariamente abrigado no Museu Oscar Niemeyer por conta da sede original se encontrar em reforma no período), em Curitiba, com curadoria de Fabrícia Jordão, no período de 9 de outubro de 2019 a 26 de abril de 2020.

2-14a edição da Bienal Internacional de Arte Contemporânea de Curitiba com o conceito curatorial "Fronteiras em Aberto", de Adolfo Montejo Navas e Tereza de Arruda. Esta edição contou com curadoria e trabalhos de profissionais não só do Brasil, como África do Sul, China, Espanha, Estados Unidos, Itália, Suíça e Uzbequistão, em mais de 60 sedes

3- A exposição Declaração de Princípios, esteve em cartaz no Museu Oscar Niemeyer de 8 de agosto a 10 de novembro, e contou com curadoria de Agnaldo Farias. A exposição mostrou trabalhos recentes do artista Geraldo Leão, assim como trabalhos de seus ex-alunos na antessala, entre eles Andréia Santos, Bruno Oliveira, Lilian Gassen, Tony Camargo, Lívia Piantavini, Willian Santos e William Machado.
} 


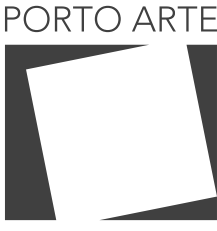

Revista de Artes Visuais

v. 25 ก. 43 Jan/jun 2020 e-ISSN: 2179-8001

educativas que ali ocorrem, pelo posicionamento crítico e político da direção da instituição, pelas aquisições ou doações que a instituição escolhe para seu acervo (assim como as que deixa de incluir), pelos patrocinadores que apoiam ela e a instituição, pelo momento histórico em que é proposta, pelo contexto sócio-cultural que a envolve...

"O museu afirma-se por meio da apresentação de grandes artistas", é o que Agnaldo Farias defende no texto curatorial de "Declaração de Princípios" como justificativa para a exposição: já era hora de homenagear o pintor com uma exposição individual em um dos centros culturais mais visitados de Curitiba. Geraldo Leão é doutor em História pela UFPR e atua como Professor do Departamento de Artes da Universidade Federal do Paraná (UFPR) localizada em Curitiba, cidade onde vive e trabalha. Já participou de diversas exposições individuais e coletivas em território nacional, assim como no exterior. Na década de 1980, seus trabalhos se caracterizam por telas de grandes dimensões, destaque no trabalho cromático e acabamento bruto. Na exposição de 2019 no MON, estão expostas pinturas em dimensões variadas de uma abstração experimental que revela um diálogo espontâneo, parcialmente planejado, entre tempo, resina, água e vívidas cores sobre a tela disposta na horizontal. No entanto, o que a exposição tem a nos contar não é somente a produção recente de Geraldo Leão, ela pretende revelar princípios também em sua postura generosa como artista e professor ao solicitar que trabalhos de ex-alunos fossem expostos na antessala, ao mesmo tempo que essa clara separação de trabalhos e lugares sugere uma relação aprendiz-mestre hierarquicamente. São princípios de curadoria quando Farias denomina a si mesmo como "curador ornamental", deixando a cargo do artista e Lilian Gassen, artista e também companheira de Leão, a expografia da antessala. Os princípios foram declarados...?

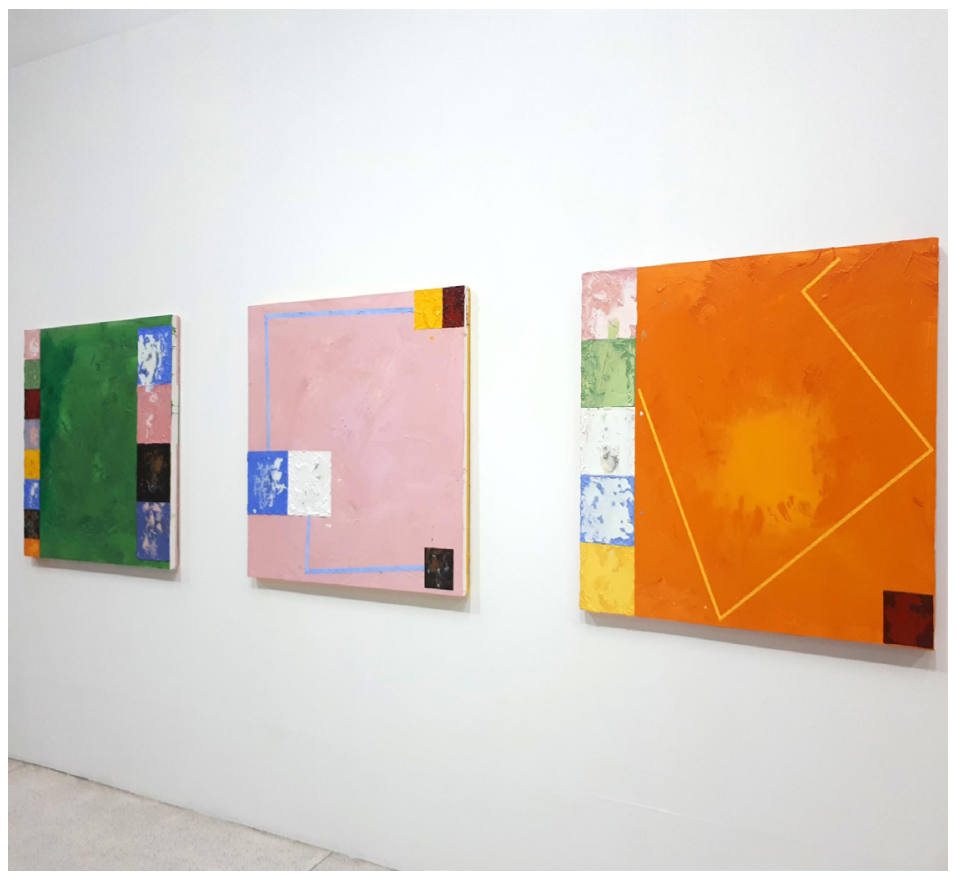




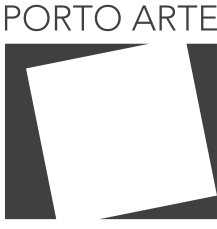

Revista de Artes Visuais

$\vee 25 n .43$

Jan/jun 2020 e-ISSN: 2179-8001

Ao mesmo tempo que Farias destaca uma produção recente de um artista local, Fabrícia Jordão, como curadora, busca no acervo do Museu de Arte Contemporânea do Paraná (MAC-PR) trabalhos que organiza em núcleos "alegóricos", "contranarrativos", e "ecopolíticos" para "Pequenos Gestos - Memórias Disruptivas" (2019-2020). E se você não sabe exatamente o que esses termos querem dizer, tudo bem, porque a exposição traz textos explicativos de cada núcleo, palavras-chave expandidas em verbetes e algumas perguntas para provocar reflexões. 0 compromisso educativo não encerra aí: cada obra é acompanhada por um trecho de fala do artista responsável e/ou texto crítico. Absolutamente todas as peças são apresentadas contextualizadas e abrem para discussões de maneira inclusiva, fazendo questão de usar as palavras certas para as discussões necessárias. A exposição é resultado de intensa pesquisa e traz destaques premiados pelo Salão Paranaense, mas não deixa de evidenciar as lacunas do acervo em núcleos tão críticos: não encontramos trabalhos de indígenas e quase não há trabalhos de artistas pretos ou pretas. Mesmo quando um trabalho traz em evidência a questão da religião afro brasileira, como a obra intitulada Ota-Oxalufan (1984), um orixá africano, a curadoria evidencia como essa questão foi silenciada por toda a crítica. $O$ texto na legenda expandida do trabalho, assinado pela curadoria e equipe MAC-PR afirma:

Diferente das demais obras aqui apresentadas, durante a pesquisa por textos críticos sobre a obra de Vilmar Nascimento, nos deparamos com a invisibilidade de um aspecto que se apresenta como fundamental ao trabalho. Como está explícito no título na obra, seu conceito relaciona-se às religiões de matrizes africanas, recupera a figura do orixá Ota-Oxalufan, enaltecendo uma ancestralidade e tradição que não são contempladas pelas narrativas eurocêntricas. A ausência desse debate na crítica de arte é sintoma de um racismo estrutural ainda presente. A recusa em transcrever textos dessa natureza reforça o compromisso do MAC-PR em se colocar como uma instituição inclusiva e plural, que estabeleça diálogos entre passado e presente, culturas e territórios, a partir da arte contemporânea.

E é escolha deliberada da curadoria posicionar essa obra no núcleo contranarrativo ao invés de ecopolítico, e o trabalho certamente faria sentido em qualquer um dos núcleos. Contudo, essa escolha evidencia ainda mais a impossibilidade da não neutralidade curatorial diante de um apagamento histórico. De forma semelhante, também a exposição "Verboamérica" (2016), proposta pelo Museo de arte latinoamericano de Buenos Aires (MALBA), organiza o acervo do museu em núcleos ${ }^{4}$ para questionar

4- Os núcleos são: En el principio; Mapas, geopolítica y poder; Ciudad, modernidad y abstracción; Ciudad letrada, ciudad violenta, ciudad imaginada; Trabajo, multitud y resistencia; Campo y periferia; Cuerpos, afectos y emancipación; América indigena, América negra. 


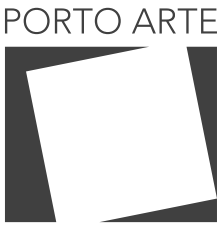

Revista de Artes Visuais

v. $25 n .43$ Jan/jun 2020 e-ISSN: 2179-8001
Figura 03 - Mapa (1994) de Carla Vendrami à esquerda, e SLU (2006) de Estevão Machado à direita, em exposição no MAC PR na sala 10 do Museu Oscar Niemeyer em outubro 2019 Imagem da autora. e contrapor a tradição de construir uma única história, linear e universal, para então apresentar mais histórias e realidades.

Os gestos artísticos se revelam inquietos em seu tempo, e ecoam sinais de um Brasil, e de um Paraná, que tentaram (tentam?) anular suas origens e marcas culturais. Contudo, encontramos no MAC-PR uma gestão comprometida diante da história da arte no Paraná, colocando-se em diálogo com os anseios do público e das produções contemporâneas. Inaugurado em 1970, está em seu projeto ser um referencial em documentação e pesquisa de arte no Paraná. Desde sua inauguração, assume a realização do Salão Paranaense, que desde 1944 acontecia sob responsabilidade do Departamento de Cultura do Estado. 0 museu desenvolve projetos experimentais em parceria com universidades, acolhendo estudantes universitários para pesquisar o acervo e propor exposições, desenvolver projetos expositivos, assim como atividades educativas, revelando uma abertura para interdisciplinaridade e comunicação entre as áreas de estudo (história, arquitetura, artes visuais) para atuar como referência na formação de profissionais do setor cultural.

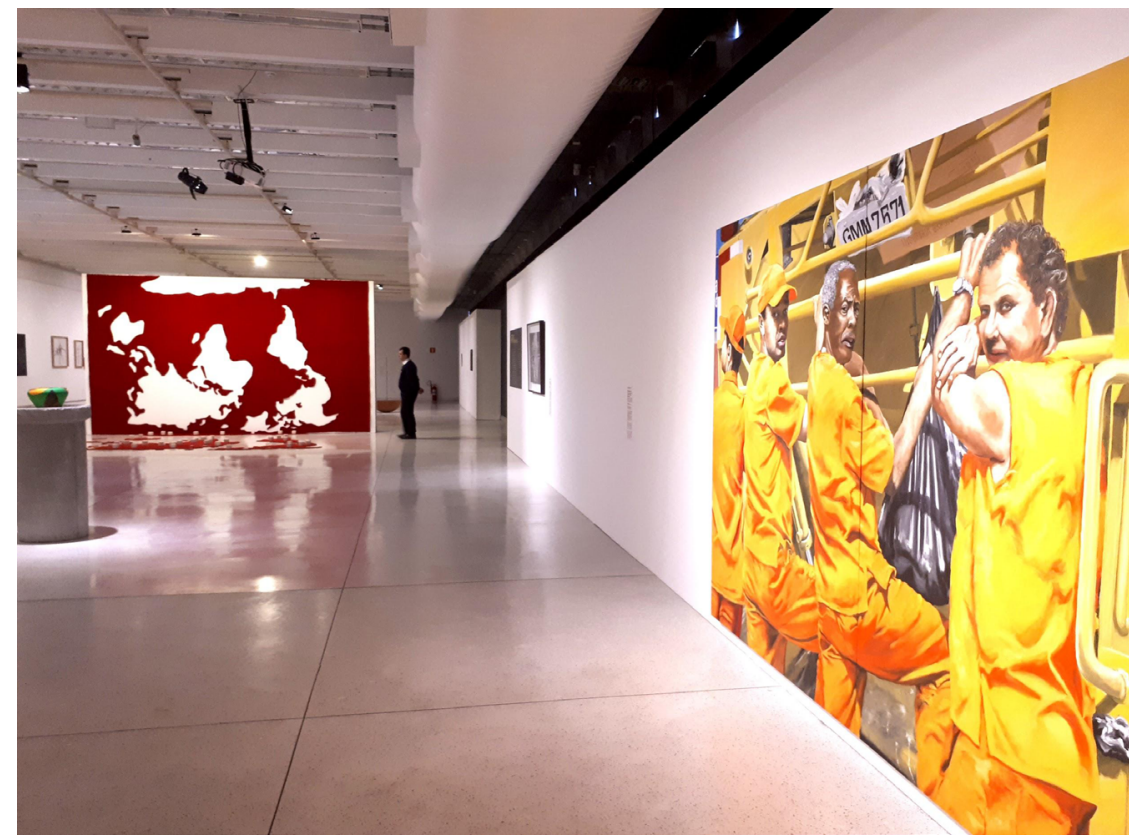

E se até aqui já não pensávamos em fronteiras, a $14^{\mathrm{a}}$ Bienal reforça o tema em seu título: Fronteiras em Aberto. Com curadoria de Adolfo Montejo Navas e Tereza de Arruda, o conceito curatorial propõe diálogos acerca da construção ou desconstrução de fronteiras no mundo contemporâneo. A Bienal Internacional de Arte Contemporânea de Curitiba tem seu surgimento em 1993 e, desde então, suas edições revelam buscas pela promoção da integração da América do Sul. Em seus temas e conceitos curatoriais, já propôs tratar de água e mapas, luz, crise, e em uma edição mais recente, uma homenagem a China. 


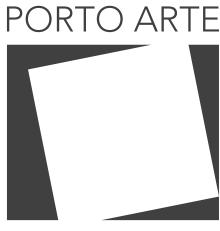

Revista de Artes Visuais

$\vee 25 n .43$

Jan/jun 2020 e-ISSN: 2179-8001

Homenagem essa que teria como propósito maior revelar as produções contemporâneas chinesas, ou através dessa revelação buscar estreitar relações comerciais? Cabe aqui apontar que a diplomacia cultural representa um forte instrumento de aproximação entre povos e nações, buscando abrir caminhos para relações comerciais através de vínculos culturais e linguísticos. Atenta a esse instrumento, a China fundou em 2004 o Instituto Confúcio, uma organização educacional pública que visa promover cultura e idioma chineses pelo mundo e já conta com mais de 500 institutos em dezenas de países. A perspectiva do Instituto para 2020 seria alcançar a marca de 1000 institutos. Não é simples evidenciar relações entre as operações comerciais e trocar culturais, mas é possível que a circulação de produtos e trabalhos artísticos entre nações provoque sentimentos de familiaridade, respeito e até confiança mútuos. Para ter uma ideia, podemos olhar para como os Estados Unidos conseguiu se estabelecer como forte referência econômica, e isso se deu em paralelo à propagação da indústria cinematográfica, que afinal divulga não somente filmes, documentários e séries, mas exemplos de consumo e comportamento através desses produtos. Portanto, são estilos de vida e consumo promovidos através da cultura. Notamos que a relação comercial entre Brasil e China, por sua vez, tem sido intensa desde 2009, e cabe lembrar como ela se intensificou durante o mandato do presidente Michel Temer: em 2016 houve o Seminário Empresarial de Alto Nível Brasil-China em Xangai, cobrindo agricultura, finanças, indústria, infraestrutura, transportes, energia e serviços; no mesmo ano ocorreu a XI Cúpula do G20 em Hangzhou a fim de promover crescimento econômico inclusivo e inovador, assim como implementar a Agenda de Desenvolvimento 2030; ainda em 2016 o intercâmbio bilateral alcançou US\$ 58,5 bilhões; em 2017 o ministro das relações exteriores visita Pequim para cumprir agenda bilateral com a China e no mesmo ano são assinados 14 atos que fortalecem relação entre os dois países: acordos para gerar negócios e investimentos no Brasil, facilitação de vistos de turismo e negócios e coprodução cinematográfica. No catálogo da Bienal de Curitiba '17, encontramos os seguintes posicionamentos: Cida Borghetti, como governadora do estado do Paraná, afirma que

A Bienal de Curitiba presta uma justa homenagem à arte de um país cujas relações com o Brasil tendem a se tornar cada vez mais próximas no decorrer deste século. Trata-se hoje do maior parceiro comercial do Brasil. A China, componente dos Brics, tem uma produção artística excelente, que se pauta pela diversidade e pela qualidade, com base num profícuo embate entre tradição e inovação/ experimentação. Como no Brasil, também na China as atividades culturais e criativas constituem um setor cada vez mais importante de representação simbólica da sociedade e de propulsão econômica com alto impacto sobre a geração de renda, de emprego e de inclusão. Em suma, de desenvolvimento. 


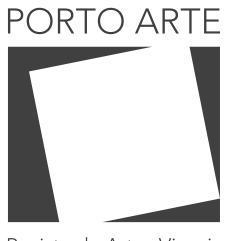

v. 25 n. 43
O prefeito de curitiba, Rafael Greca de Macedo, destaca que

um novo caminho se abre para nossa cidade. 0 caminho do desenvolvimento econômico da grande potência asiática, uma espécie de Nova Rota da Seda, capaz de atravessar continentes e mares e nos unir - para além das muralhas - a Hangzhou, cidade irmã, Beijing, Nanquim e Xangai.

Tício Escobar, curador da bienal, afirma que "a bienal permite a possibilidade de traçar diferentes constelações entre estes mundos que se distanciam e se aproximam, que se cruzam e se ajustam em diferentes ocasiões e lugares". Também curadores, Fang Zhenning e Liu Chunfeng destacam essa mostra como

a primeira mostra de arte contemporânea chinesa de grande escala no Brasil, possivelmente a primeira na América do Sul. 0 status quo da arte chinesa acompanha o ritmo do país, simbolizando avanço, inovação, compartilhamento e visão do futuro.

Vemos, então, o valor que essa aproximação cultural representa para as autoridades envolvidas no evento, como instrumento e sinal de progresso entre países emergentes do bloco BRICS, o qual foi fundado em 2009 e também inclui, além de Brasil e China, Rússia, Índia e África do Sul. Apesar de configurar um assunto complexo e muito interessante, não é o propósito deste texto investigar a fundo a diplomacia cultural entre Brasil e outros países de economia emergente. Porém, pensando nas potencialidades da diplomacia cultural, cabe levantar algumas perguntas: o que divulgar? Por quê? Onde? De que forma e com qual frequência? Deixe essas questões marinando, pois as fronteiras que a $14^{a}$ edição da Bienal de Curitiba traz são múltiplas: geográficas, geracionais, relacionais, políticas, econômicas, sociais... A edição homenageia agora os países do bloco BRICS, priorizando a exposição de obras de artistas dessas nacionalidades. No Museu Oscar Niemeyer, são seis salas expositivas dedicadas à Bienal (uma delas como parte do MAC-PR) e ainda algumas obras ocupam espaços de circulação, como o já mencionado $A$ World of Fairytale. Esta obra constrói mundos tridimensionais, autônomos em formas e cores partindo da desconstrução da cartografia bidimensional do mapa mundi, nesse sentido se mostrando similar à obra de Carla Vendrami, Mapa (1994), presente no núcleo contranarrativo de "Pequenos Gestos". A obra de Vendrami, visível na terceira imagem deste texto, traz a representação do mapa mundi, ainda que eurocêntrico, de cabeça para baixo, com a representação marítima em vermelho na parede, e a representação terrestre dos continentes e ilhas, também em vermelho, no chão. Sobre as áreas terrestres, vemos diversos dados brancos, e todos os lados dos dados mostram o número seis. A fala da artista trazida na legenda expandida da obra é a seguinte: 


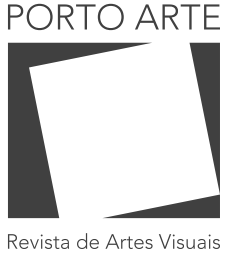

v. 25 n. 43 Jan/jun 2020 e-ISSN: 2179-8001

Eu comecei a pensar no mapa como se ele fosse um quadro. De qualquer forma, um mapa não é uma representação real - quanto maior a área representada, mais deformação ela vai dar. [...] Recortando assim, você tem mais ideia do volume e o recorte do mapa mostra não só a distribuição de massas de água e terra, mas também o valor político.

Enquanto Vendrami faz uma composição monocromática destacando o contraste do vermelho do carpete com o branco da parede e do piso, de certa forma traz o mapa para uma unidade visual; a qual é impossível na representação fiel do globo na bidimensionalidade de um mapa. Os dados trazem essa informação do jogo político, lembrando War, o popular jogo de tabuleiro. A bidimensionalidade é abraçada, mas desafiada no quase espelhamento entre parede e chão. Por sua vez, Hongbo utiliza da técnica de cola e dobra de camadas de papel, como as tradicionais lanternas chinesas, para atingir um material compacto que, depois de esculpido, ele pode manusear, abrir, esticar e expor como quiser. Nos chama a atenção que cada peça é um país - diferente de Vendrami, o artista foge da unidade visual pela cor e opta pela pluralidade nas peças multicoloridas e independentes uma da outra no espaço, e o posicionamento delas se intercala entre abertas e fechadas, ora evidenciando o contorno do país, ora ocultando. Pode-se reconhecer nessas peças o arquétipo da flor de lótus, sugerindo um florescimento diante de nós em diversas cores e tamanhos. Mas não somente a flor, o aspecto formal da instalação acaba nos lembrando exatamente o que une margens e territórios e expande fronteiras: a ponte.

Em uma palestra em que desenvolve uma leitura sobre o habitar, Heidegger ${ }^{5}$ traz a ponte como o que não se situa num lugar, pois "é da própria ponte que surge um lugar". Quando Hongbo dá independência formal aos países, desenvolvendo cada um em um complexo de papel colorido colado, desintegrando-os da unidade "planeta" e removendo a conexão oceânica, marítima, ou continental, entre eles, ele coloca cada país em uma autonomia: seja aberto para que sua face seja revelada, seja fechado nele mesmo, ou de faces para o chão. Cada país pode ser uma forma autônoma, mas a relação a que ele se propõe no todo pode ser mais ou menos aberta para uma revelação, ou comunicação. Até porque o artista faz algumas escolhas pontuais, como evidenciar a China e o Brasil próximos do centro, os únicos abertos evidenciando o contorno dos países, como um diálogo em aberto. E essa é a questão do mundo de Hongbo: é um mundo fora da cartografia, sem fronteiras e em movimento. Cada país não é um lugar, mas de onde surgem lugares. E toda essa discussão de fronteira, espaços e culturas é trazida especialmente em diálogo com outros espaços dispositivos, pois esta obra está deslocada de uma sala, ou curadoria, específica e provoca esse diálogo visual, espacial e conceitual não somente com a mostra da qual faz parte, mas com as obras das mostras das outras exposições ao seu redor. Essa obra e, especialmente, seu posicionamento, causa um efeito de transgressão de fronteiras com ainda mais potência do que obras da Bienal se propuseram a causar.

5- HEIDEGGER, M. 1954 


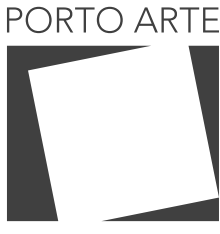

Revista de Artes Visuais

$\vee 25 n .43$

Jan/jun 2020 e-ISSN: 2179-8001

Sendo assim, vemos surgir lugares e perguntas nesse encontro de obras e exposições; são três instituições propondo narrativas e reflexões diversas em um espaço compartilhado, bastante próximo. Uma mostra direcionada a PRINCÍPIOS, outra direcionada a GESTOS e MEMÓRIA, e outra direcionada a FRONTEIRAS. E se olharmos atentamente à fotografia apresentada, existe uma figura humana ali. Um guarda de sala. Talvez essa pessoa não seja notada quando circulamos pelo espaço museal, mas se ela está ali é porque cumpre uma função: garantir que a ordem e integridade das peças expostas sejam mantidas. Pois o contato não é permitido, a interação - na maior parte das vezes - não é permitida. Os objetos nesse espaço não fazem parte da vida cotidiana, do mundo vivido, são objetos que compõe outra realidade. A vigilância se faz necessária para que dois mundos permaneçam apartados. Fronteiras conceituais se expandem das próprias exposições, mas elas de fato são abertas? Os gestos se misturam e marcam práticas de curadoria e montagem que, inevitavelmente, não se enquadram mais num museu modernista. 0 conflito é quase irônico, já que Oscar Niemeyer é referência justamente por sua arquitetura modernista, com uso de muito concreto e vastos espaços. E, por mais que uma corrente modernista da arquitetura busque a funcionalidade, acima de tudo, como as "máquinas de morar" de Le Corbusier, a arquitetura de Niemeyer é composta por linhas onduladas, desenho e cores pontuais, em busca de uma poética também sensível. A prática curatorial mais recorrente no museu modernista, ou também chamado de cubo branco, busca apresentar menos obras, em um posicionamento ideal (na altura dos olhos de quem observa) com um espaçamento calculado entre elas, para que a fruição de cada uma seja exclusiva. Essa prática é o padrão desde o século XX, sendo o MoMA de Nova York considerado um marco institucional da produção moderna. Essa ainda é a prática presente nas exposições do MON até hoje.

As obras das exposições (FÉ NA CRISE PAU NA GENTE na fachada da exposição; antessala entreaberta em "Declaração de Princípios"; e A World of Fairytale deslocado das outras salas da Bienal) fora de seus espaços delimitados, em aberto, em relação com o restante do museu, afrontam a proposta quase higienista do cubo branco e nos provoca. O museu modernista buscava, essencialmente, um tipo de neutralidade e universalidade, partindo do quadrado, do branco, das molduras e pedestais como recursos de poder, poder expor qualquer trabalho de qualquer artista, mas separando do mundo externo, da bagunça do ateliê, da agitação urbana das ruas... Essa busca por delimitações evidentes, espaçamento e até isolamento, conversa com as questões insurgentes do século XXI? De que forma é possível reconstruir nesse espaço diálogos que acolham a pluralidade e o aspecto relacional da contemporaneidade? Quando pensamos na instituição que recebe outras duas instituições culturais temporariamente em seu espaço, como ela pode se abrir para essa recepção e continuar a ser ela mesma? Ou ainda, ela se constitui apesar da pluralidade ou por causa dela? Notamos que não se trata apenas de espaço, mas de ações, posturas, comportamento. Essa pluralidade ocorre de uma maneira espontânea, pois a visitação das salas expositivas não é a única forma de estar no museu. Além do parcão atrás do edifício, que fica bastante movimentado em fins de semana, os espaços do vão livre e ao redor do salão de eventos também 


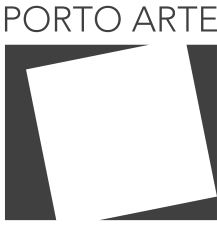

Revista de Artes Visuais

$\vee 25 n .43$

Jan/jun 2020 e-ISSN: 2179-8001

são ocupados por grupos de adolescentes que se encontram para praticar coreografias de dança, por exemplo. Essa forma de ocupar o espaço acontece organicamente, sem decorrer de uma iniciativa da organização do museu, sem qualquer planejamento de cunho urbanístico e arquitetônico. 0 museu é aberto. 0 museu é aberto?

Assim como o museu não consegue ser neutro em seu espaço, as curadorias também não podem, nem deveriam, ser neutras. Harald Szeeman, como Diretor Artístico da "Documenta 5" (1972), constituiu um marco no que conhecemos hoje como curadoria e acolheu as demandas dos artistas da época, trabalhando em conjunto e decidindo deixar aparecer as operações que se passam por trás de uma exposição, ao contrário da postura comum, de tentar manter uma aparência de que as exposições seriam autônomas. Nessa exposição, até mesmo as críticas direcionadas a ela, feitas pelos artistas Robert Smithson e Daniel Buren, são incorporadas no catálogo do evento ${ }^{6}$, não somente se tornando públicas, mas também acolhidas como parte daquele processo.

A pretensa neutralidade estética e institucional dos museus faz buscar ainda outras atitudes, outras nomenclaturas. Eilean Hooper-Greenhill ${ }^{7}$ problematiza o conceito de "cultura" para expandir o conceito de "cultura visual". A autora constrói esse conceito enfatizando que mapas e coleções de museus partilham a função de ativar a imagem e a imaginação de estruturas de poder se tornando materiais. A lente da cultura visual, que costumava ser predominantemente restringida aos estudos midiáticos e comunicacionais, agora observa as narrativas acerca dos objetos e coleções das instituições e conecta essas diferentes coleções a um assunto mais amplo em estudos museais. Hooper-Greenhill finaliza sua tese voltando-se ao que ela chama de "pós-museu", que seria uma nova forma de fazer um museu. É um processo, uma experiência, que toma formas arquitetônicas diversas, centra nos espaços, necessidades e ambições das comunidades. 0 pós-museu incorpora diversas vozes e perspectivas para produzir eventos e exposições dinâmicos, os quais atuam como parte de uma dinâmica conjunta que possibilita a incorporação de várias vozes e perspectivas ao museu, de modo que o conhecimento deixa de ser monolítico e unificado, tornando-se fragmentado e multivocal: não existe uma perspectiva única e necessária, mas sim uma cacofonia de vozes que apresentam uma variedade de visões, experiências e valores. Dessa forma, destaca que as funções pedagógicas de museus podem ser analisadas ao revisar tanto o que é dito como a forma que é dito. Tanto a coleção, o acervo do museu, como a forma como é curado nas exposições.

O pós-museu é consciente dele mesmo, criticamente consciente dele mesmo: olha para as lacunas de seu passado, assim como busca dar conta de preenchê-las e atender às necessidades da comunidade no presente. As exposições do espaço físico não são suficientes, é preciso acolher e incluir vozes, abrir-se para discussões, diversificar atividades. A autora anuncia o fim da fase do museu como um grande colecionador. Essa autoconsciência configura uma ampliação do objetivo de adquirir e curar objetos para focar no uso deles ao invés de sua acumulação. Portanto, valoriza uma prática curatorial que busca selecionar, organizar e expor conteúdos visuais e textuais, produ- 


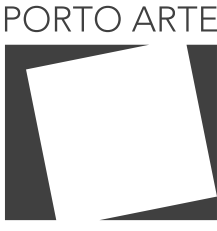

Revista de Artes Visuais

$\vee 25 n .43$

Jan/jun 2020 e-ISSN: 2179-8001

zindo caminhos para interpretações e narrativas, acolhendo também elementos não visuais que compõem a cultura, como cantos, danças e tradições.

Quando compreendemos os objetivos do pós-museu, notamos que se aproximam do conceito de constelação pós-colonial, proposto pelo curador nigeriano Okwui Enwezor (2003), primeiro curador de origem africana na Biennale di Venezia, em 120 anos de história da mesma. Essa constelação, de acordo com o curador, seria um espaço para expandir concepções históricas, sociais, econômicas, artísticas em novas e diversas relações. Através da constelação pós-colonial, as narrativas podem ser questionadas, reformuladas, funcionando radicalmente diferente de uma linha do tempo linear com hierarquia de linguagens. Assim, é possível reescrever a história propondo várias outras histórias, trazendo visibilidade a mais grupos e propostas visuais. Um ótimo exemplo é a exposição "Black models: from Géricault to Matisse" (2019), do Musée d'Orsay, com equipe curatorial formada por Cécile Debray, Stéphane Guégan, Denise Murrell e Isolde Pludermacher. Quando lembramos que a palavra curadoria nasce do "curar", ou cuidar, encontramos nessa exposição esse esforço de curar feridas coloniais e trazer para primeiro plano as identidades de modelos pretos representados em produções artísticas (pintura, escultura, fotografia) desde o momento da abolição da escravatura, entre 1794 e 1848, até produções pós-guerra e contemporâneas. A partir dessa exposição, descobrimos que a mulher preta retratada em Olympia (1863), de Édourad Manet, se chama Laure. Outro esforço feito, além de trazer as identidades dos sujeitos retratados, diz respeito ao uso de termos pejorativos, como nègre, negrèsse e mulâtre, pois quando os termos envolvem a ideia de negro e negra, costumam estar vinculadas a ideias de algo negativo, obscuro, ou indesejado, como ovelha negra, magia negra, humor negro, etc. Portanto, obras que incluíam algum desses termos foram renomeadas, como Une mulâtresse [Uma mulata] (1824), de Eugène Delacroix, torna-se Étude d'après le modèle Aspasie [Estudo à partir da modelo Aspasie]. Esses gestos revelam a potência da prática curatorial através de ações de pesquisa e visibilidade.

$\mathrm{O}$ que vemos na imagem que ilustra o início deste texto no MON evidencia três mostras de três instituições (MON, MAC-PR e Bienal) que poderia, potencialmente, direcionar para uma constelação pós-colonial. A pluralidade de discursos e obras reunidas em um mesmo espaço institucional, registrada pela foto em meados de outubro de 2019 , revela camadas de história, posicionamentos, curadorias, patrocínios, escolhas de acervo. É evidente que não vivemos mais o momento da neutralidade modernista, e as instituições não precisam mais se esconder atrás de exposições "autônomas". Se, por um lado, temos o esforço de ressignificação que "Pequenos Gestos" traz, seguindo exemplos de "Verboamérica" e "Black models"; temos inclinações bastante diferentes nas propostas de Agnaldo Farias e da $14^{\mathrm{a}}$ Bienal. Se olharmos para além do caráter curatorial, vemos que cada uma dessas instituições é composta por uma equipe educativa própria, cada uma com suas pesquisas e ações; ainda que exista uma colaboração na formação e capacitação de profissionais do setor educativo, por exemplo, na abertura de exposições tanto do MAC-PR, quanto do MON e da Bienal de Curitiba, a dinâmica de recebimento de grupos para mediação segue algumas regras que distancia essas instituições. 0 compartilhamento de espaço parece favorável para os visitantes que 


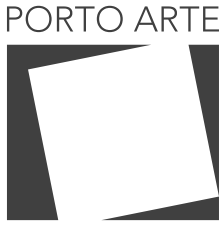

Revista de Artes Visuais

v. 25 ก. 43 Jan/jun 2020 e-ISSN: 2179-8001

pagam, nesse período, somente uma entrada para ver exposições de três instituições, mas será que o mesmo pode ser dito para os setores? Existe uma circulação e construção colaborativa, desde acervo e referência, pesquisa, curadoria, até o educativo? Se esses grupos profissionais não constroem uma possibilidade colaborativa, o próprio acolhimento e participação ativa da comunidade ficam comprometidos, e a construção de novas narrativas na contemporaneidade continua restrita aos círculos privilegiados, econômica e intelectualmente. 0 espaço sugere pontes, mas o comportamento hesita. Gaston Bachelard ${ }^{8}$ aponta para uma dialética do interior e do exterior, afirmando que

o exterior e o interior formam uma dialética de esquartejamento, e a geometria evidente dessa dialética nos cega tão logo a introduzimos em âmbitos metafóricos. Ela tem a nitidez crucial da dialética do sim e do não, que tudo decide.

Hooper-Greenhill também aponta que o museu modernista se impõe a partir de divisões binárias, como interior e exterior. Lembrando da menção ao guarda de sala visto na fotografia, compreendemos que as galerias, ou salas expositivas, configuram espaços de consumo, visualização e aprendizado, mas sob o controle comportamental, que deve ser silencioso, discreto. Há uma clara separação entre espaços para ver e espaços em que o toque é permitido: aquele espaço especial para pessoas cegas ou com baixa visibilidade, como o pátio de esculturas. A dialética do exterior e interior esquarteja porque também hierarquiza o acesso e as relações estéticas.

Entrar num museu que temporariamente abriga, além das suas, exposições de duas outras instituições, e impor uma dialética do interior e do exterior seria a tentativa de isolamento modernista: obras intocáveis, uma exposição de cada vez, a sala isolada do mundo externo na proteção ideal do museu; seria esquartejar as potencialidades de conversa e diálogo de propostas, públicos, acervos, atividades. Ainda que isso esteja oculto pela cortina imaginária das exposições autônomas, chega ao público em um entruncamento de informações e atividades. Na contramão, o que Bachelard evidencia é um ser espiralado, que percorre caminhos no exterior em busca de um interior, mas o centro nunca é de fato atingido: o movimento não cessa. 0 ser é desfixado, a história é desfixada, as narrativas são desfixadas. E o que não é fixo é passível de transição e fluidez. Retomando World of Fairytale e a sugestão visual e simbólica da ponte, dialogamos com a superfície do ser, em que

0 ser quer se manifestar e quer se ocultar, os movimentos de fechamento e abertura são tão numerosos, tão frequentemente invertidos, tão carregados de hesitação, que poderíamos concluir com esta fórmula: o homem é o ser entreaberto ${ }^{9}$. 


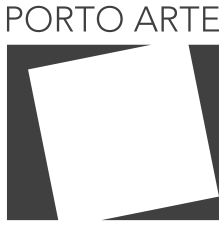

Revista de Artes Visuais

$\vee 25 n .43$

Jan/jun 2020 e-ISSN: 2179-8001

Afinal, como deve funcionar um pós-museu na prática? Hooper-Greenhill, em Museums and The Interpretation of Visual Culture (2000) traz alguns casos para propor leituras críticas. Os casos apresentados neste texto, mostram ainda outra realidade. E é possível levantar ainda mais casos para interpretar posturas de pós-museu. Portanto, pode não ser o caso de definir um modelo a seguir, pelo contrário, o museu modernista já veio como um modelo a ser respeitado e replicado, e o movimento nos últimos anos foi de questionar isso e propor alternativas, olhar para contextos e necessidades locais, para não perpetuar uma busca pelo formato universal. A realidade que foi apresentada neste recorte mostra um momento de constelação institucional que não foi completamente intencional da forma como aconteceu: o acolhimento da Bienal é periódico e regular, mas receber o MAC-PR é temporário. Pode não ter havido planejamentos para atuar nessa pluralidade com colaborações mais próximas, mas também não significa que não possa haver uma abertura para trabalhos, pesquisas e ações em conjunto nos próximos momentos. Aliás, isso deveria ficar cada vez mais real e palpável; ou então propor conceitos de ultrapassar fronteiras no centro de um projeto ficará registrado apenas como mais um discurso utópico, ou uma fachada conceitual e artística para vincular relações comerciais. 0 pós-museu se faz entreaberto quando se constitui como processo; a constelação pós-colonial se faz entreaberta ao viabilizar novas e diversas relações sociais, artísticas e históricas. E o ser entreaberto é aquele que, como Hélio Oiticica, vê que o museu é o mundo.

\section{Referências}

BACHELARD, Gaston. A Poética do Espaço. São Paulo: Martins Fontes, 2003.

ENWEZOR, Okwui. The Postcolonial Constellation: Contemporary Art in a State of Permanent Transition. Research in African Literatures, Bloomington: Indiana University Press, vol. 34, n. 4, p. 57-82, 2003.

HEIDEGGER, Martin. Construir, Habitar, Pensar. Conferência pronunciada por ocasião da "Segunda Reunião de Darmastad", publicada em Vortäge und Aufsätze, G. Neske, Pfullingen, 1954. Tradução de Marcia Sá Cavalcante Schuback. Disponível em <http://www.fau.usp.br/wp-content/uploads/2016/12/heidegger_construir_habitar_pensar.pdf> Acesso em 04 fev. 2020.

HOOPER-GREENHILL, Eilean. Museums and the Interpretation of Visual Culture. Routledge: London and New York, 2000.

LEÃO, Geraldo. In: ENCICLOPÉDIA Itaú Cultural de Arte e Cultura Brasileiras. São Paulo: Itaú Cultural, 2020. Disponível em: <http://enciclopedia.itaucultural.org.br/pessoa10184/geraldo-leao>. Acesso em: 25 fev 2020. Verbete da Enciclopédia.

MUSEU DE ARTE CONTEMPORÂNEA DO PARANÁ. História - Um Novo MAC. Disponível em: <http://www.mac.pr.gov.br/Pagina/Historia> Acesso em: 20 fev. 2020.

PRANDO, Felipe Cardoso de Mello. Campo neutral: limites e tensões entre práticas artísticas, curatoriais e instituições de arte. 2016. Tese (Doutorado em Poéticas Visuais) - Escola de Comunicações e Artes, Universidade de São Paulo, São Paulo, 2016. doi:10.11606/T.27.2016.tde-13092016-104137. Acesso em: 2020-02-06. 


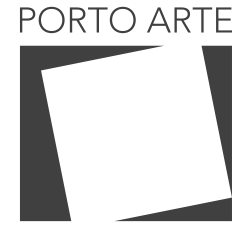

Revista de Artes Visuais

v. $25 \mathrm{n} .43$

Jan/jun 2020

e-ISSN: 2179-8001

\section{Joanna Brolhani}

Mestranda em Teoria e História das Artes Visuais, PPGAV - CEART - UDESC

Texto submetido em: 23/05/2020

Texto aprovado em: $30 / 06 / 2020$

Texto publicado em: 25/06/2020 